Environmental Biology of Fishes Vol. 12, No. 3, pp. 231-236, 1985

(C) Dr W. Junk Publishers, Dordrecht.

\title{
The significance of biparental care in the brown bullhead, Ictalurus nebulosus
}

\author{
Lawrence S. Blumer \\ Division of Biological Sciences and Museum of Zoology, University of Michigan, Ann Arbor, MI 48109, \\ U.S.A.
}

Keywords: North American catfishes, Parental care, Reproductive behavior, Sex roles, Evolution of behavior

\section{Synopsis}

Parental care in the brown bullhead is characterized by variation in the participation of each sex. Most broods are attended by both sexes, but some are attended by a male alone, or rarely, a female alone. Two care-givers were more successful than one alone in fostering offspring survival. However, there was no significant difference between two care-givers and one alone in the proportion of time that broods were unattended. Potential brood predators were chased less frequently by one adult alone than by adults aided by their mate. This difference may be unimportant since two adults simultaneously attended their brood only $19 \%$ of the time. Males alone attended their broods a significantly greater proportion of time than did either males or females aided by their mates. This difference suggests that males alone sustain a greater cost of caregiving (starvation and therefore reduced future reproduction) than do males aided by their mates. Thus, males alone may more often leave broods (and not return) than males that are aided in care-giving. The differential success observed may be due to a difference in the likelihood that the male (the principal caregiver) leaves the brood permanently, rather than differences in the quality of care one or two adults provide. I suggest that two care-givers are more successful than one because the net benefits of care-giving exceed the net benefits of leaving for males when aided by their mates.

\section{Introduction}

Biparental care, participation by both sexes in care-giving, is absent in the chondrichthyan fishes (Wourms 1977) but occurs in approximately $6 \%$ of bony fish families ( 24 of the 424 families). These families represent $27 \%$ of the 89 families known to have parental care of any form (Blumer 1982a). Biparental care among bony fishes is viewed as an evolutionary enigma by some investigators (Emlen 1973, Williams 1975) because guarding is the major form of care-giving (Blumer 1979, 1982a) and one adult would seem to be almost as good as two (Williams 1975). This view of biparental care in fishes is rebutted with the suggestion that extreme predation pressures and severe competition for breeding sites may make care-giving by two adults a necessity for effective brood defense (Barlow 1974, Baylis 1981). Both points of view suffer from the implicit assumption that biparental care should evolve and be maintained only when two adults can foster offspring survival considerably better than one adult alone. Two adults need only do slightly better than one alone if the alternative activities for each sex (such as further mating or feeding) yield a poorer reproductive success than remaining with their mate's offspring (Blumer \& Dominey, unpublished). 
Understanding the evolution and maintenance of biparental care requires both an assessment of the difference in benefit to offspring conferred by one versus two adults and the value of alternative activities for each sex (Perrone 1975).

The brown bullhead, Ictalurus nebulosus, exhibits biparental care with variation between broods in female participation in care-giving. In one population, biparental care was observed at 50 $(56.2 \%)$ broods, while $35(39.3 \%)$ broods were attended by a male alone. Males usually participate in care-giving, but four broods $(4.5 \%)$ were attended by a female alone (Blumer 1982b). This natural variation in care-giving behavior offered an opportunity to determine the relative success of biparental care compared to uniparental care. In this paper, I address the question, are two adults more successful in fostering offspring survival than one adult alone. The factors affecting each sex and the relative importance of alternative activities are considered elsewhere (see Blumer 1982b).

\section{Methods and materials}

This study was conducted on a natural population of brown bullheads (Ictalurus nebulosus) at Munro Lake, Cheboygan County, Michigan (N45 $37^{\prime}$, $\left.\mathrm{W} 48^{\circ} 41^{\prime}\right)$. Ninety-eight different broods were observed under natural conditions during a five year period 1978-1982. All observations were made on individually tagged adults (Blumer 1982b). Details on the lake environment and methods of observation are given in Blumer (1982b).

Ideally, a measurement of success in care-giving would involve an accurate tabulation of the number of eggs (embryos) present at early stages of development and the number of juveniles living at the end of parental care. Comparisons between broods attended by one or two adults could then be made in terms of rates of brood survival. Unfortunately, these data were difficult to obtain without creating considerable disturbance at a nest and increasing the likelihood of nest failures. Bullhead eggs are deposited in a three-dimensional gelatinous mass of irregular shape which made tabulation by photography problematic. Furthermore, juveniles stayed in dense schools which were not easily photographed or counted. An alternative to a rate of survival measure is an absolute evaluation of survival: either a brood (or part of a brood) survived to the juvenile stage of development, or it died or disappeared before the normal end of caregiving. Broods first observed as eggs (embryos) or larvae were the only cases for which an evaluation of success could be made. An indirect measure of success was based on the relative persistence of broods, the number of days a brood survived. The frequency of nest attendance, frequency of nest intrusions and intruder chasing, and behavioral changes in adults when their mates were absent from the nest are considered as proximate factors affecting offspring survival. Intrusions occurred when fishes other than the parents approached a brood to within one meter $(50 \mathrm{~cm}$ in the case of minnows (Cyprinidae) and juvenile yellow perch (Perca flavescens). Data on intrusions were collected during $42 \mathrm{~h}$ of observation on seven biparental broods and $25 \mathrm{~h}$ on 13 male alone broods.

In this paper, I refer to costs and benefits of alternative reproductive activities as the ultimate factors molding behavior. I make no claim to be able to measure such costs or benefits on an absolute scale but only to make comparisons. Ideally, an appropriate unit of measure for evolutionary costs or benefits would be numbers of offspring (standardized for offspring size and other qualities). Costs and benefits are often estimated by measuring variables that are expected to have specific effects on lifetime reproduction. For example, adult starvation during parental care is expected to have a negative effect on future reproduction and is therefore considered a cost in evolutionary terms. Organisms strive to facilitate their genetic representation in future generations by reproducing and then often by aiding their offspring. The results of activities which increase one's production of offspring (and increase one's genetic representation in future generations) are benefits. Costs are the results of activities which have the opposite effects. Specific activities can have both potential costs and benefits so the net benefits of alternatives must be considered to make comparisons. The net benefits of an activity refer to the net benefits that 
accrue to each individual adult who performs that activity.

Unless otherwise noted, means are given with one standard error. Nonparametric statistical analyses (Conover 1971) are used throughout this paper. Categorical data were analyzed with Chisquare tests and two sample comparisons were made with Mann-Whitney U tests (corresponding to Student's T-tests). The significance levels for one-tailed tests are reported when specific directional differences were expected.

\section{Results}

Success, as measured by survival from the egg or larval stages to the juvenile period of development, was evaluated for 62 broods. Among these broods, offspring in $13(21 \%)$ survived to the juvenile period of development and the termination of parental care. Only one of the successful broods was attended by one adult alone. There is a highly significant relationship between the number of care-givers and the survival of a brood to the juvenile period of development $\left(\mathrm{X}^{2}=8.997, \alpha=0.003\right.$, $\mathrm{n}=60$, Table 1 ). Two care-givers were more successful than one. These data are potentially biased because 24 broods were observed on only one day before they disappeared and most (17) of these short-lived broods were categorized as having only a single care-giver. However, there is still a significant relationship between the number of caregivers and brood survival among broods observed

Table 1. The relationship between number of care-givers and brood survival. The numbers in parentheses are the expected values for the null hypothesis of independence between brood survival and number of care-givers.

\begin{tabular}{llll}
\hline Survival & \multicolumn{2}{l}{ Number of care-givers } & \multirow{2}{*}{ Total } \\
\cline { 2 - 3 } & One & Two & \\
\hline Yes & $1(6.3)$ & $12(6.7)$ & 13 \\
No & $28(22.7)$ & $19(24.3)$ & 47 \\
Total & 29 & 31 & 60 \\
\hline
\end{tabular}

$\mathrm{X}^{2}=8.997, \alpha=0.003$ for two or more days $\left(\mathrm{X}^{2}=4.349, \alpha=0.04, \mathrm{n}=36\right.$, Table 2). In this analysis all of the one care-giver broods were attended by a male.

The number of days that broods persisted was significantly greater with two adult attendants $(6.9 \pm 1.0$ days $)$ than with one adult $(2.7 \pm 0.9)$ (Mann-Whitney $U$, one-tailed $\alpha=0.0003$, one adult $n=22$, two adults $n=21$ ). All broods were first observed as eggs or larvae, and observations were made until a brood disappeared or the termination of parental care. Among the subset of broods that did not survive to the termination of parental care, the same pattern of persistence was observed. Broods attended by two adults persisted significantly more days ( $4.6 \pm 1.1$ days) than those attended by one adult (1.9 \pm 0.3 days) (MannWhitney $\mathrm{U}$, one-tailed $\alpha=0.007$, one adult $\mathrm{n}=21$, two adults $n=13$ ). The proximate causes for the differential success of two care-givers compared to one may be due to differences in ability to protect offspring against predators. However, an increased cost of care-giving for a male or female alone could result in nest desertion and then predation. These factors are not mutually exclusive and both are considered below.

Anti-predation activities are an important function of parental care in the brown bullhead (Blumer 1982b), so differences in the quality of brood defense may account for the differential success observed. The proportion of time during which a brood was unattended was not significantly different for broods attended by two adults $(19.8 \pm 0.1 \%, \mathbf{n}=18)$ compared to those attended

Table 2. The relationship between number of care-givers and brood survival for broods observed on two or more days. The numbers in parentheses are the expected values for the null hypothesis of independence between brood success and number of care-givers.

\begin{tabular}{llll}
\hline Survival & \multicolumn{2}{l}{ Number of care-givers } & \multirow{2}{*}{ Total } \\
\cline { 2 - 3 } & One & Two \\
\hline Yes & $1(4.3)$ & $12(8.7)$ & 13 \\
No & $11(7.7)$ & $12(15.3)$ & 23 \\
Total & 12 & 24 & 36 \\
\hline
\end{tabular}

$\mathrm{X}^{2}=4.349, \alpha=0.04$ 
by a male alone $(10.4 \pm 0.1 \%, \mathrm{n}=9$ ) (MannWhitney $U$, two-tailed $\alpha>0.10$ based on continuous one hour observation periods on 27 broods for a total of $100 \mathrm{~h}$ ). The rate of intrusions by potential predators was not significantly different between broods attended by one or two adults $\left(\mathrm{X}^{2}=0.944\right.$ $\alpha>0.10$ ). This comparison was based on the number of intrusions observed at broods attended by a male alone during $25 \mathrm{~h}$ (96 intrusions) and an estimate of the number of intrusions that would have occurred at biparental broods if observations had been limited to $25 \mathrm{~h}$ ( 83 intrusions). Potential predators on broods were conspecific adults; sunfishes, Lepomis gibbosus, L. macrochirus, and Ambloplites rupestris, bass, Micropterus salmoides, minnows, Pimephales and Notropis spp., and juvenile yellow perch, Perca flavescens. Intruding fishes were chased from biparental broods more frequently than from broods attended by a male alone $\left(X^{2}=12.116, \alpha=0.0005\right.$, Table 3$)$. This was due almost entirely to the activities of female care-givers (Blumer 1982b), but females were most likely to chase intruders when the male was simultaneously present $\left(\mathrm{X}^{2}=5.227, \alpha=0.02\right.$, Table 4$)$. Among the broods attended by both adults, both care-givers were present simultaneously only $19.2 \pm 0.1 \%(\mathrm{n}=18)$ of the time. Actual predation was rarely observed as it occurred, but among 16 observations, 14 occurred in the absence of any care-giving adults. At least during the early stages of embryonic development, I found no evidence that brood predators would be capable of overwhelming the defense of a lone adult since most

Table 3. The relationship between number of care-givers and intruder chasing. The numbers in parentheses are the expected values for the null hypothesis of independence between number of carc-givers and intruder chasing.

\begin{tabular}{llcr}
\hline Chase given & \multicolumn{2}{c}{ Number of care-givers } & \multirow{2}{*}{ Total } \\
\cline { 2 - 3 } & \multicolumn{2}{l}{ One } & Two \\
\hline Yes & $5(15.1)$ & $32(21.9)$ & 37 \\
No & $91(80.9)$ & $108(118.1)$ & 199 \\
Total & 96 & 140 & 236 \\
\hline
\end{tabular}

$\mathrm{X}^{2}=12.116, \alpha=0.0005$
Table 4. The relationship between mate presence and intruder chasing by females. The intrusions considered in this table are a subset of those given in Table 3. Mate presence describes the presence or absence of the male at the time an intrusion occurred. These observations $(18.5 \mathrm{~h})$ were made on six broods attended by both sexes. The numbers in parentheses are the expected values for the null hypothesis of independence between mate presence and intruder chasing.

\begin{tabular}{llcl}
\hline Chase given & \multicolumn{2}{c}{ Mate presence } & Total \\
\cline { 2 - 3 } & Female alone & Female with mate \\
\hline Yes & $13(17.4)$ & $10(5.6)$ & 23 \\
No & $43(38.6)$ & $8(12.4)$ & 51 \\
Total & 56 & 18 & 74 \\
\hline
\end{tabular}

$\overline{\mathrm{X}^{2}}=5.227, \alpha=0.02$

nests were in shelters (but this possibility cannot be ruled out).

The advantage that two care-givers have compared to one alone may have less to do with providing better care than with the advantages (to each sex) of sharing the costs of care-giving. When both sexes participated in care-giving, the proportion of time that either sex spent in care-giving activities was less than that of a lone care-giver (MannWhitney $U$, one-tailed $\alpha<0.05$ for 18 males and $\alpha<0.001$ for 18 females observed with their mates compared to 9 males observed alone). Females spent a small proportion of time in care-giving $(34.1 \pm 8.6 \%)$ but a female's presence reduced the proportion of time her mate spent in care-giving. Males aided by their mates spent $64.0 \pm 8.8 \%$ of their time in care-giving compared to $89.6 \pm 6.4 \%$ for males alone.

\section{Discussion}

Although intruders were less likely to be chased from broods attended by a male alone than when two adults attended a brood, I have no evidence that these differences lead to the differential brood survival observed. The absence of significant differences in the proportion of time that broods were unattended and the small proportion of time during which two adults simultaneously attended off- 
spring suggest minimal differences in the quality of brood protection provided by two adults and males alone. When brood predation on bullheads was actually observed, it was almost always in the absence of any care-giver (Blumer 1982b).

I did not document differences in the costs of parental care between lone males and males aided by their mates. However, the difference in proportion of time spent in care-giving and the fact that males do not feed while attending a brood (Blumer 1982b) suggest a difference in care-giving costs. This greater cost of care-giving for males alone may be sufficient to make the net benefits of care-giving less than the net benefits of leaving the brood. Here I am refering to net benefits to adults in ultimate terms, lifetime reproduction and genetic representation in future generations. Among the broods that did not survive to the juvenile period of development, most did not survive past the egg (embryo) stages (Blumer 1982b). If brood failures result from desertion followed by predation rather than the other way around, most brood failures would be expected early in care-giving. At that time, most of a male's parental investment would have yet to be made, so the net benefit of leaving the brood would be the greatest (Dawkins \& Carlisle 1976). Other factors (such as susceptibility to fungal infection or inadequate gas exchange) may account for brood failures occurring at the egg stages of development. However, masses of developing embryos appeared alive and healthy just prior to their disappearance (Blumer 1982b).

Differential success between two care-givers and one adult alone is usually attributed to differences in the quality of care one or two adults can provide (Barlow 1974, Perrone \& Zaret 1979). Keenleyside (1978) conducted aquarium experiments with the biparental cichlid Herotilapia multispinosa in which one adult was removed from a care-giving pair and offspring survival evaluated. In the presence of brood predators, two adults were more successful than one alone, but the cause of this difference was not investigated. Perrone \& Zaret (1979) noted that biparental care would enable one adult to leave the brood and feed while the other attended the offspring. I suggest that this apparent effect of biparental care may be the cause of the differential success of two adults versus one. The quality of parental care that two adults provide may be no better than that provided by one adult (Williams 1975). Although predation is a likely consequence in the absence of any care-giver (Baylis 1974, Perrone 1975, Blumer 1982b), the cost of parental care (in terms of future reproduction) for one adult alone may be sufficiently great that the net benefits of care-giving are outweighed by the net benefits of leaving. This situation is most likely to occur early in a care-giving period, early in a breeding season, or early in the reproductive lifetime of an individual when alternative reproductive activities may be best pursued.

\section{Acknowledgments}

This work was supported by awards from the Museum of Zoology Hinsdale Scholarship, Rackham School of Graduate Studies, and the Division of Biological Sciences at the University of Michigan, the University of Michigan Biological Station, Sigma Xi, the Theodore Roosevelt Memorial Fund of the American Museum of Natural History, and the Raney Fund of the American Society of Ichthyologists and Herpetologists. I thank my field assistants, John Findley Alan Rudolph, Craig and Noreen Flory, Todd Paddock, Fred Koelher, Tony Hainault, John Hutto, Mark Southern, and Chris Wood for their hard work and patience. I also thank the Michigan Department of Natural Resources for permission to tag fishes, the staff of the University of Michigan Biological Station, Mr. Herb Billings of F.W. Ritter Sons Co., GilbertBennett Manufacturing Co., McArthur Bros., Mr. and Mrs. R.J. Gifford, and the residents of Munro Lake, Michigan. I am indebted to G.R. Smith, R.A. Nussbaum, W.G. Holmes, R.D. Alexander, and my fellow graduate students for advice, comments and criticisms. I thank M. Perrone and an anonymous referee for critical comments on a draft of this paper. Special thanks to K.F. Keyes for assistance beyond the call of duty. 


\section{References cited}

Barlow, G.W. 1974. Contrasts in social behavior between Central American cichlid fishes and coral-reef surgeon fishes. Amer. Zool. 14: 9-34.

Baylis, J.R. 1974. The behavior and ecology of Herotilapia multispinosa (Teleostei, Cichlidae). Z. Tierpsychol. 34: 115146.

Baylis, J.R. 1981. The evolution of parental care in fishes, with reference to Darwin's rule of male sexual selection. Env. Biol. Fish. 6: 223-251.

Blumer, L.S. 1979. Male parental care in the bony fishes. Q. R. Biol. 54: 149-161.

Blumer, L.S. 1982a. A bibliography and categorization of bony fishes exhibiting parental care. Zool. J. Linnean Soc. Lond 75: $1-22$.

Blumer, L.S. 1982b. Parental care and reproductive ecology of the North American catfish, Ictalurus nebulosus. Ph.D. Thesis, University of Michigan, Ann Arbor. 160 pp.

Conover, W.J. 1971. Practical nonparametric statistics. Wiley, New York. 462 pp.
Dawkins, R. \& T.R. Carlisle. 1976. Parental investment, mate desertion and a fallacy. Nature 262: 131-133.

Emlen, J.M. 1973. Ecology: an evolutionary approach. Addison-Wesley, Reading. 493 pp.

Keenleyside, M.H.A. 1978. Parental care behavior in fishes and birds. pp. 3-29. In: E.S. Reese \& F.J. Lighter (ed.) Contrasts in Behavior, Wiley, New York.

Perrone, M. 1975. The relation between mate choice and parental investment patterns in fish who brood their young: theory and a case study. Ph.D. Thesis, University of Washington, Seattle. $143 \mathrm{pp}$.

Perrone, M. \& T.M. Zaret. 1979. Parental care patterns of fishes. Amer. Nat. 113: 351-361.

Williams, G.C. 1975. Sex and evolution. Princeton University Press, Princeton. $200 \mathrm{pp}$.

Wourms, J.P. 1977. Reproduction and development in chondrichthyan fishes. Amer. Zool. 17: 379-410

Received 6.4.1983 Accepted 15.2.1984 